\title{
BMJ Open Systematic review and meta-analysis of opioid antagonists for smoking cessation
}

\author{
Sean P David, ${ }^{1,2}$ Isabella M Chu, ${ }^{2}$ Tim Lancaster, ${ }^{3}$ Lindsay F Stead, ${ }^{3}$ \\ A Eden Evins, ${ }^{4}$ Judith J Prochaska ${ }^{5}$
}

To cite: David SP, Chu IM, Lancaster T, et al. Systematic review and meta-analysis of opioid antagonists for smoking cessation. BMJ Open 2014;4:e004393. doi:10.1136/bmjopen-2013004393

- Prepublication history for this paper is available online. To view these files please visit the journal online (http://dx.doi.org/10.1136/ bmjopen-2013-004393).

Received 8 November 2013 Revised 29 January 2014 Accepted 20 February 2014

\section{CrossMark}

\author{
${ }^{1}$ Center for Education in \\ Family \& Community \\ Medicine, Stanford \\ University, Stanford, \\ California, USA \\ ${ }^{2}$ Stanford General Medical \\ Disciplines, Stanford \\ University, Stanford, \\ California, USA \\ ${ }^{3}$ Department of Primary Care \\ Health Sciences, University of \\ Oxford, Oxford, UK \\ ${ }^{4}$ Department of Psychiatry, \\ Massachusetts General \\ Hospital, Boston, \\ Massachusetts, USA \\ ${ }^{5}$ Stanford Prevention \\ Research Center, Stanford \\ University, Stanford, \\ California, USA
}

Correspondence to Dr Sean P David; spdavid@stanford.edu

\begin{abstract}
Objectives: This meta-analysis sought to evaluate the efficacy of opioid antagonists in promoting long-term smoking cessation. Post-treatment abstinence was examined as a secondary outcome and effects on withdrawal symptoms, craving and reduced consumption were also explored.

Design: The search strategy for this meta-analysis included clinical trials (published and unpublished data) in the Cochrane Tobacco Addiction Group Specialized Register and MEDLINE.

Participants: Adult smokers.

Interventions: We included randomised trials comparing opioid antagonists to placebo or an alternative therapy for smoking cessation and reported data on abstinence for a minimum of 6 months.
\end{abstract}

\section{Primary and secondary outcome measures:}

Outcomes included smoking abstinence at long-term follow-up (primary); abstinence at end of treatment (secondary); and effects on withdrawal, craving and smoking consumption (exploratory).

Results: 8 trials with a total of 1213 participants were included. Half the trials examined the benefit of adding naltrexone versus placebo to nicotine replacement therapy (NRT). There was no significant difference between naltrexone and placebo alone (relative risk (RR) $1.00 ; 95 \% \mathrm{Cl} 0.66$ to 1.51 ) or as an adjunct to NRT (RR $0.95 ; 95 \%$ Cl 0.70 to 1.30 ), with an overall pooled estimate of RR $0.97 ; 95 \% \mathrm{Cl} 0.76$ to 1.24 . Findings for naltrexone effects on withdrawal, craving and reduced smoking were equivocal.

Conclusions: The findings indicate no beneficial effect of naltrexone alone or as an adjunct to NRT on short-term or long-term smoking abstinence. While further trials may narrow the confidence limits, they are unlikely to appreciably alter the conclusion.

\section{BACKGROUND}

Tobacco use is the leading preventable cause of death. ${ }^{1}$ US clinical practice guidelines recommend the use of pharmacotherapy for quitting smoking. ${ }^{2}$ Medications with demonstrable efficacy for cessation include nicotine replacement therapy (NRT) in the form of

\section{Strengths and limitations of this study}

- This meta-analysis compares opioid antagonists to placebo or an alternative therapy for smoking cessation and reports data on abstinence for a minimum of 6 months.

- The meta-analysis includes published and unpublished results from eight trials with a total of 1213 participants.

- The findings indicate no beneficial effect of naltrexone alone or as an adjunct to nicotine replacement therapy on short-term or long-term smoking abstinence, which suggests that further investment in clinical trials of naltrexone for this indication are unlikely to change the conclusion that this medication does not provide a clinically significant benefit for helping smokers stop smoking.

- Inability to refute published claims of differential benefits of naltrexone for smoking cessation in subgroups defined by gender or secondary benefits on reduction of postcessation weight gain.

gum, patch, lozenge, inhaler and nasal spray with pooled relative risk (RR) for any NRT of $1.60,95 \%$ CI 1.53 to $1.68^{3}$; bupropion with $\mathrm{RR}=1.69$, CI 1.53 to $1.85^{4}$; and varenicline with $\mathrm{RR}=2.27$, CI 2.02 to $2.55 .^{3} 5$ Effective second-line treatments include nortriptyline (RR 2.03; CI 1.48 to 2.78$)^{4}$ and clonidine (OR 1.89, CI 1.30 to 2.74$).{ }^{6}$ Yet, long-term quit rates with these pharmacotherapies are relatively modest, in the range of $19-36.5 \% .^{2}$ With relapse as the norm, there is continued interest in medication development and discovery of pharmacological agents for assisting tobacco cessation.

Naltrexone (Narpan, Revia, Vivitrol, with half-life of $240 \mathrm{~min}^{7}$ ), a long-acting opioid antagonist, is a marketed drug that blunts the effects of narcotics such as heroin, meperidine, morphine and oxycodone and is effective in the treatment of alcohol dependence. 89 Naltrexone occupies $\mu$-opioid receptors, which putatively diminishes the activation of 
mesolimbic dopamine and therefore may reduce craving for nicotine. With different mechanisms of action, it has been postulated that NRT and naltrexone could produce additive effects for treating nicotine withdrawal and preventing relapse. Since opioid antagonists are known to precipitate nicotine withdrawal in nicotine dependent animals, ${ }^{10-13}$ administering NRT in conjunction may attenuate any increased withdrawal, dysphoria and sedation caused by naloxone and naltrexone. Naloxone (Narcan, with half-life $30-100 \mathrm{~min}^{14}$ ) is a short-acting opioid antagonist routinely administered to reverse the acute effects of narcotic overdose. Naloxone has been shown to block the reinforcing properties of nicotine and precipitate physical and affective symptoms of nicotine withdrawal in rodent studies. ${ }^{10-13}$ Buprenorphine (Buprenex, Subutex, Suboxone (combination buprenorphine/naltrexone), Butrans, with half-life $24-60 \mathrm{~h})^{15}$ is a mixed agonist-antagonist used for the treatment of opioid dependence. Although less widely studied for this indication, naloxone and buprenorphine have also been evaluated as potential smoking cessation aids and are included in this review.

Concerns regarding potential adverse effects have led to US Food and Drug Administration (FDA) black box warnings for the cessation medications bupropion and varenicline. With respect to the adverse event profile of opioid antagonists when used in the treatment of opioid dependence, serious adverse effects are uncommon but there is an FDA black box warning regarding potential hepatotoxicity for naltrexone. Nervous system side effects reported in $>10 \%$ of patients during treatment for opioid dependence have included headaches, nervousness, anxiety, difficulty sleeping and low energy; those reported in $<10 \%$ of patients include loss of appetite, increased energy, irritability and dizziness. Asthenia, agitation, hyperkinesia, nervousness, fatigue, restlessness, confusion, disorientation and somnolence have been reported rarely. Side effects of buprenorphine are similar to those of other opioids and include nausea, vomiting and constipation.

While opioid antagonists are typically used in the treatment of opioid dependence, the primary objective of this systematic review and meta-analysis was to evaluate the long-term efficacy of opioid antagonists (ie, naltrexone, naloxone and buprenorphine), alone or in combination with NRT, in promoting smoking cessation. The secondary objective was to evaluate the short-term (posttreatment) abstinence effects. Specific opioid antagonists were considered separately rather than grouping the medications as a class. We tested the hypotheses that opioid antagonists: (1) are more effective than placebo in promoting early and sustained abstinence from smoking and (2) when used in combination with NRT are more effective than NRT alone in promoting early and sustained abstinence from smoking. We also summarise the literature on the effects of opioid antagonists in treating withdrawal symptoms, attenuating the reinforcing value of smoking and reducing ad libitum smoking.
The results of this systematic review and meta-analyses have been published in a recent Cochrane Review. ${ }^{16}$

\section{METHODS}

Search strategy and study selection

We included randomised controlled trials of opioid antagonists with adult smokers that reported smoking status at least 6 months after intervention to assess the efficacy for long-term cessation. For the secondary outcome, we also considered randomised controlled trials of opioid antagonists reporting abstinence at end of treatment or that reported the outcomes of nicotine withdrawal, reinforcing properties of smoking or ad libitum smoking. The medications evaluated were naltrexone, naloxone, buprenorphine or other opioid antagonists, with or without concurrent use of NRT.

To identify eligible studies, we searched the Tobacco Addiction group Specialized Register in April 2013 using the terms 'naloxone' or 'naltrexone' or 'buprenorphine' or 'opioid antagonist' or 'opiate antagonist' or 'narcotic antagonist' in the title or abstract or as keywords. At the time of the search, the Register included the results of searches of the Cochrane Central Register of Controlled trials (CENTRAL), issue 3, 2013; MEDLINE (via OVID) through 29 March 2013; EMBASE (via OVID) through 16 March 2013 and PsycINFO (via OVID) through 1 April 2013. An additional search of MEDLINE (via OVID through 17 April 2013) used the terms (explode "Narcotic-Antagonists"/all subheadings) AND ("Smoking-Cessation"/all subheadings OR "Tobacco-Use-Disorder"/all subheadings OR "Smoking"/all subheadings). Two authors cross-checked the studies to insure they met the inclusion criteria. Discrepancies were resolved by mutual consent including a third author, as required. We noted reasons for the noninclusion of studies. Details of the search are in the PRISMA Diagram (figure 1).

\section{Data extraction}

Data extraction included: basic study characteristics (sample size, design, blinding, method of randomisation and location), sample characteristics (cigarettes/day and intention to quit), tobacco measures and outcomes, reported adverse effects and attrition. The primary outcome measure of interest was abstinence at 6 months or longer, with preference given to the longest follow-up available. Abstinence at end of treatment was a secondary outcome. We used a sustained cessation rate in preference to point prevalence, and biochemical verification of self-reported quitting where reported (eg, carbon monoxide (CO) and cotinine). Other outcome measures of interest included withdrawal, reinforcing or hedonic effects of smoking, mood states and ad libitum smoking.

\section{Data analysis}

For the abstinence outcomes, we calculated RRs of abstinence at longest follow-up using as the 
Figure 1 PRISMA diagram of literature search and data extraction
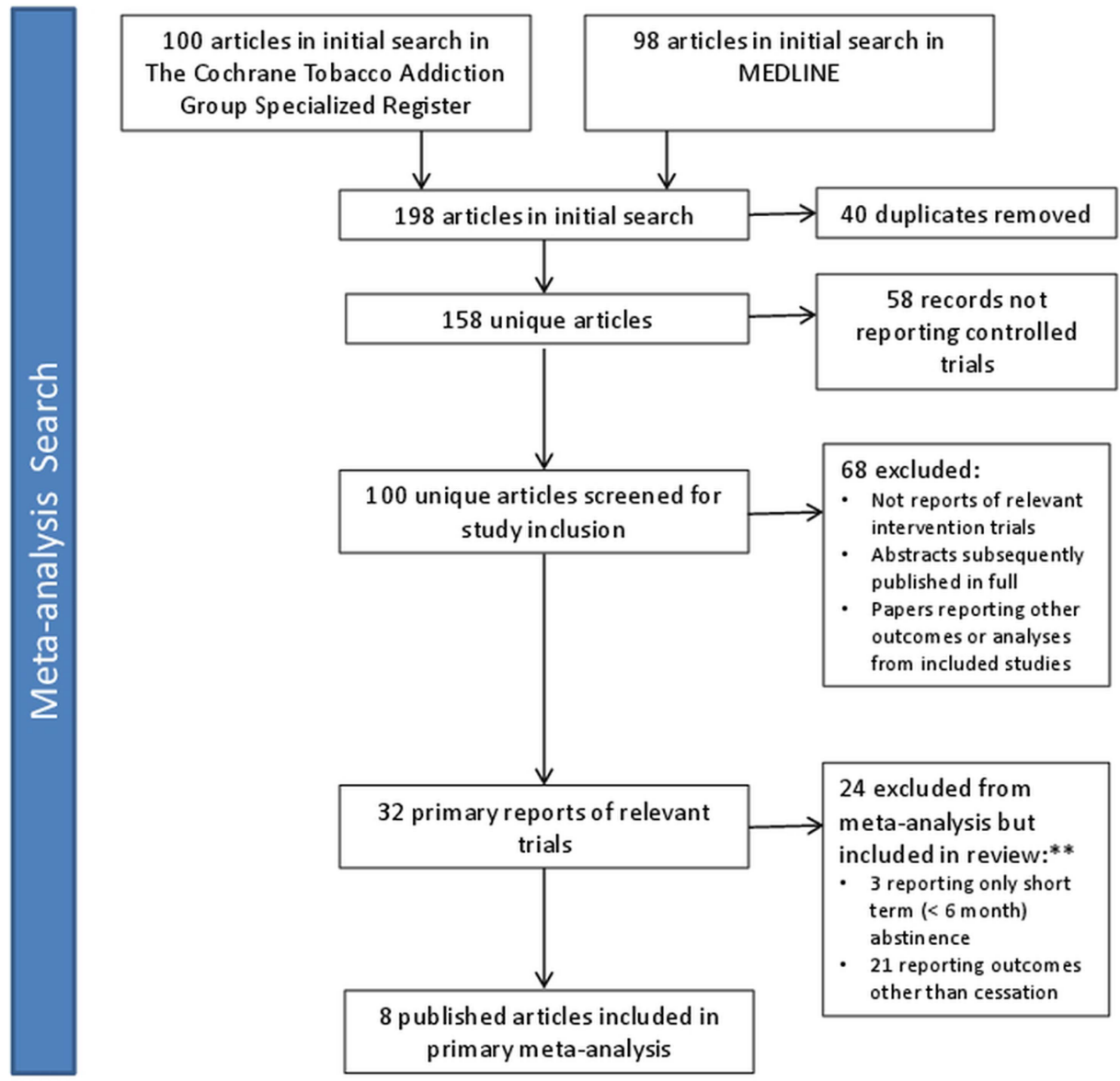

-Register holds reports of controlled trials on smoking cessation identified from searches of CENTRAL, MED LINE, EMBASE and other sources including conference abstracts. See Specialized Register http://onlinelibrary.wiley.com/o/cochrane/clabout/articles/TOBACCO/frame.html

**24 studies excluded from meta-analyses were included in review for sensitivity analyses of short-term outcomes ( $k=3)$ and reporting outcomes other than abstinence.

denominators the numbers of patients randomised to each arm excluding any deaths and treating those who dropped out or were lost to follow-up as continuing to smoke. We noted any deaths and adverse events in the results tables. If necessary, we contacted authors for clarification of specific points. Separately, we combined the results of studies evaluating short-term and long-term cessation using the Mantel-Haenszel fixed-effect model for pooling risk ratios. Effect sizes were calculated for all trials together and by whether or not NRT was used. In a sensitivity analysis, we estimated the effect at end of treatment of adding in the results from studies excluded due to lack of long-term follow-up. For assessment of risk of bias, we evaluated studies on the basis of random sequence generation (selection bias), allocation concealment (selection bias), blinding (performance bias and detection bias) and incomplete outcome data (attrition bias). ${ }^{17}$ None of the trials of buprenorphine or naloxone were eligible for inclusion in meta-analyses of abstinence because of lack of sufficient follow-up or available abstinence outcomes. Therefore, we report abstinence results only for naltrexone. Procedures varied and few studies reported on measures of withdrawal, craving and smoking reduction for buprenorphine, naloxone and naltrexone; hence, these outcomes were narratively summarised. Characteristics of all included and excluded studies are published in the Cochrane Review. ${ }^{16}$

\section{FINDINGS}

\section{Long-term abstinence}

We identified eight trials evaluating naltrexone and reporting long-term abstinence rates with a total of 1213 participants (table 1). ${ }^{18-26}$ Three studies examined naltrexone monotherapy relative to placebo; four studies examined naltrexone as an adjunct to NRT or placebo; and one study had four arms, which allowed for examination of naltrexone alone versus as an adjunct to NRT with matched placebo conditions for both arms. ${ }^{25}$ There was no evidence of heterogeneity in subgroups with or without NRT. Naltrexone dose ranged from 25 to $150 \mathrm{mg}$ daily. Five trials provided cessation counselling with the medication of either brief (15-20 min) ${ }^{19} 25$ or more extended duration. ${ }^{18} 20{ }^{24}$ Four studies biochem-

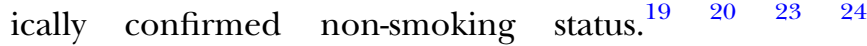
Abstinence data were unpublished for two of the studies 


\begin{tabular}{|c|c|c|c|c|c|c|c|c|c|c|}
\hline \multicolumn{6}{|l|}{ Trial description } & \multicolumn{5}{|l|}{ Risk of bias } \\
\hline Trial & $\begin{array}{l}\text { Follow-up } \\
\text { time point for } \\
\text { abstinence }\end{array}$ & Region & Treatment & $\begin{array}{l}\text { Number of } \\
\text { participants } \\
\text { at baseline }\end{array}$ & $\begin{array}{l}\text { Number } \\
\text { participants } \\
\text { at longest } \\
\text { follow-up }\end{array}$ & $\begin{array}{l}\text { Biochemical } \\
\text { validation }\end{array}$ & $\begin{array}{l}\text { Random } \\
\text { sequence } \\
\text { generation }\end{array}$ & $\begin{array}{l}\text { Allocation } \\
\text { concealment }\end{array}$ & $\begin{array}{l}\text { Incomplete } \\
\text { outcome } \\
\text { data }\end{array}$ & Blinding \\
\hline Baltieri et $a^{P^{1}}$ & $\begin{array}{l}12 \text { weeks } \\
6 \text { months }\end{array}$ & Brazil & $\begin{array}{l}\text { 1. Naltrexone } 50 \mathrm{mg} / \text { day for } 12 \text { weeks } \\
\text { 2. Placebo } \\
\text { 3. Topiramate up to } 300 \mathrm{mg} / \text { day } \\
\text { (not used in this review) }\end{array}$ & 65 & 28 & No & Unclear & Low & Unclear & Low \\
\hline Covey et $a l^{18}$ & $\begin{array}{l}4 \text { weeks } \\
6 \text { months }\end{array}$ & USA & $\begin{array}{l}\text { 1. Naltrexone } 25 \mathrm{mg} / \text { day at least } 3 \text { days before } \\
\text { quit date, increased to } 50-75 \mathrm{mg} / \text { day on quit } \\
\text { date and continued for } 4 \text { weeks } \\
\text { 2. Placebo }\end{array}$ & 80 & 54 & Yes & Unclear & Unclear & High & Low \\
\hline King et $a^{P^{0}}$ & $\begin{array}{l}8 \text { weeks } \\
24 \text { weeks }\end{array}$ & USA & $\begin{array}{l}\text { 1. Naltrexone } 25 \mathrm{mg} \text { for } 3 \text { days then } 50 \mathrm{mg} \text { for } \\
2 \mathrm{~m} \text {, nicotine patch for } 1 \mathrm{~m} \\
\text { 2. Placebo and nicotine patch }\end{array}$ & 110 & 89 & Yes & Low & Low & Low & Low \\
\hline King et $a P^{4}$ & $\begin{array}{l}12 \text { weeks } \\
6 \text { months } \\
12 \text { months }\end{array}$ & USA & $\begin{array}{l}\text { 1. Naltrexone }(50 \mathrm{mg} / \text { day }) \times 12 \text { weeks plus } \\
\text { nicotine patch }(21 \mathrm{mg} / \text { day } \times 2 \text { weeks, } 14 \mathrm{mg} / \\
\text { day } \times 1 \text { week, } 7 \mathrm{mg} / \text { day } \times 1 \text { week) } \\
\text { 2. Placebo } \times 12 \text { weeks plus } 12 \text { weeks plus } \\
\text { nicotine patch (same schedule) }\end{array}$ & 315 & 238 & Yes & Low & Low & Low & Low \\
\hline Meszaros et $a f^{22}$ & 12 weeks & USA & $\begin{array}{l}\text { 1. Naltrexone } 3 \text { times/week ( } 100 \mathrm{mg} \text { Monday } \\
\text { and Tuesday; } 150 \mathrm{mg} \text { Friday) } \times 3 \text { months } \\
\text { 2. Placebo (same schedule) }\end{array}$ & 79 & Not given & No & Unclear & Unclear & Unclear & Unclear \\
\hline O'Malley et al ${ }^{19}$ & 12 months & USA & $\begin{array}{l}\text { 1. Naltrexone } 100 \mathrm{mg} \\
\text { 2. Naltrexone } 50 \mathrm{mg} \\
\text { 3. Naltrexone } 25 \mathrm{mg} \\
\text { 4. Placebo } \\
\text { All participants also received } 21 \mathrm{mg} \text { NRT } \\
\text { patch } 6 \text { weeks, initial } 45 \text { min counselling } \\
\text { session, weekly } 15 \text { min counselling sessions for } \\
6 \text { weeks, plus self-help materials including } \\
\text { dietary and exercise tips }\end{array}$ & 385 & 295 & Yes & Low & Low & Low & Low \\
\hline Toll et $a^{26}$ & $\begin{array}{l}6 \text { weeks } \\
6 \text { months }\end{array}$ & USA & $\begin{array}{l}\text { 1. Naltrexone }(25 \mathrm{mg} / \text { day }) \times 27 \text { weeks } \\
\text { 2. Placebo } 27 \text { weeks }\end{array}$ & 172 & 58 & Yes & Low & Low & Low & Low \\
\hline Wong et $a{ }^{25}$ & $\begin{array}{l}12 \text { weeks } \\
6 \text { months }\end{array}$ & USA & $\begin{array}{l}\text { 1. Naltrexone } 50 \mathrm{mg} / \text { day for } 12 \text { weeks } \\
\text { 2. Nicotine patch }(21 \mathrm{mg} \text { for } 8 \text { weeks } / 14 \mathrm{mg} \text { for } \\
4 \text { weeks)+placebo pill } \\
\text { 3. Naltrexone }(50 \mathrm{mg} / \text { day })+\text { nicotine patch } \\
(21 / 14) \text { for } 12 \text { weeks } \\
\text { 4. Placebo pill for } 12 \text { weeks } \\
\text { All groups received weekly counselling. } \\
\text { No placebo patches used }\end{array}$ & 100 & 69 & Yes & Low & Low & Unclear & Unclear \\
\hline
\end{tabular}

Risk of bias assessments-biochemical validation indicates cotinine or exhaled carbon monoxide verification of abstinence evident from publication or investigator correspondence ('yes'/'no'). Risk of reporting bias and risk of bias was assessed for lack of random sequence generation (selection bias), allocation concealment (selection bias), incompletely reported outcome data (attrition bias) or lack of or incomplete blinding (performance bias and detection bias), ('high'/'low'/'unclear'), respectively.

NRT, nicotine replacement therapy. 
and obtained directly from the authors. ${ }^{21}{ }^{22}$ For one of the studies, part of a multicentre trial with 350 participants enrolled at five centres in the USA, the authors only published the results from the Mayo Clinic site, which enrolled 100 people but would not provide unpublished data for the other study sites upon repeated requests ( $\mathrm{R}$ Croop, personal communication to Dr. Robert Croop of DuPont Merck Pharmaceutical Company, 2000). Despite our attempts to obtain unpublished data for the other 250 participants, the funder DuPont, has not disclosed further results. ${ }^{16}$ In one study, ${ }^{19}$ there were three different treatment arms of 25, 50 and $100 \mathrm{mg}$ naltrexone. The 50 and $100 \mathrm{mg}$ groups were combined and included in the meta-analysis, however, we conducted a sensitivity analysis and including the $25 \mathrm{mg}$ arm did not significantly change the results-as previously reported. ${ }^{16}$

The pooled estimate for the eight trials gave no evidence of a treatment effect (RR 0.97 ; $95 \%$ CI 0.76 to 1.24 ; table 2). For the five studies that examined naltrexone alone versus placebo $(n=450)$, the pooled estimate was RR 1.00; 95\% CI 0.66 to 1.51 (table 2), ${ }^{18} 21-2325$ and the estimate was not sensitive to exclusion of the two studies with unpublished data lacking biochemical validation of abstinence. ${ }^{21}{ }^{22}$ For the four studies that examined naltrexone versus placebo as an adjunct to NRT $(\mathrm{n}=768)$, the pooled estimate was RR $0.95 ; 95 \%$ CI 0.70 to $1.30 .^{19} 202425$

Three trials raised the possibility that there could be a difference in effect by sex, with women showing more evidence of a benefit than men for smoking cessation in two trials ${ }^{18} 20$ and showing less of a benefit in a third. ${ }^{24}$ In one trial, naltrexone showed a greater effect in preventing weight gain for women than men. ${ }^{24}$ The other five abstinence studies did not report quit rates for men and women separately 22242627 and a summary estimate could not be calculated without risk of reporting bias.

\section{Short-term abstinence}

Similar to the analysis of long-term abstinence effects, there was no evidence of an early treatment effect and with a slightly narrower CI (RR $1.03 ; 95 \%$ CI 0.88 to 1.22, table 3). Three studies in addition to the eight trials in the main analysis were found to only report short-term outcomes. ${ }^{27-29}$ Inclusion of the 116 participants from these trials did not greatly alter the estimate (RR $1.09,95 \%$ CI 0.93 to 1.27 ).

\section{Risk of bias in included studies}

Studies included in the meta-analysis were evaluated on their attempts to control bias in randomisation, allocation, assessment and analysis. None of the eight studies were judged at high risk for selection bias due to inadequate randomisation or allocation concealment procedures, but three did not report methods in sufficient detail for the possibility of allocation bias to be discounted. ${ }^{18} 21{ }^{22}$ Two of these studies have only been reported as abstracts with limited methodological detail. All studies were described as double blind. The longterm cessation studies confirmed abstinence with biochemical verification, with two exceptions. ${ }^{21}{ }^{22}$ Five studies reported exhaled CO verification, ${ }^{19} \begin{array}{llll}20 & 24 & 25 & 29\end{array}$ and one study reported plasma cotinine concentration. ${ }^{18}$ This study had high attrition in both groups and greater attrition earlier in the naltrexone group: 10 people in the naltrexone group and 2 people in the placebo group were considered treatment failures because they dropped out prior to the target quit day. ${ }^{18}$

\section{Withdrawal, hedonic effects and smoking reduction}

Overall, findings were mixed for effects of naltrexone, naloxone and buprenorphine on measures of nicotine withdrawal, nicotine reward and ad libitum smoking. Ten studies indicated no effect of naltrexone on withdrawal symptom scores. ${ }^{18} \quad 20 \quad 23 \quad 25 \quad 29-35$ Five studies reported reductions in withdrawal or smoking urge. $^{19} 20243436$ For one of the trials, the effect was found only at the $100 \mathrm{mg}$ dose compared to placebo and not at lower doses. ${ }^{19}$ Additionally, three trials indicated diminished withdrawal symptoms following provocative smoking cues during sustained abstinence, ${ }^{37-39}$ and one trial reported that naltrexone reduced ethanol's enhancing effect on smoking urge symptoms but naltrexone did not have a significant main effect on smoking urges. ${ }^{40}$ For naloxone, two studies found no significant difference in withdrawal symptoms or mood states relative to placebo, ${ }^{4142}$ and another study showed an increased urge to smoke (craving) and tiredness at lower dosages of naloxone. ${ }^{43}$

Studies evaluating the reinforcing effects of smoking also were mixed. Two studies found no effect of naltrexone on self-reported satisfaction from smoking ${ }^{30}$ or smoking reinforcement. ${ }^{38} 3944$ Other studies found significant reduction in self-reported satisfaction with smoking, ${ }^{41} \quad{ }^{45}$ increased negative mood following smoking ${ }^{32}$; increased lightheadedness, dizziness and head rush following a cigarette, ${ }^{33}$ and significantly reduced postcigarette craving. ${ }^{33}$ For naloxone, two studies found no effect on the reinforcing properties of smoking cigarettes. ${ }^{42} 46$

Lastly, the results regarding ad libitum smoking were mixed. There were no significant effects of naltrexone on ad libitum smoking in three small trials. ${ }^{30-32}$ However, six trials demonstrated statistically significant reductions in the number of cigarettes smoked ad libitum. ${ }^{33} 34 \quad 36384748$ Five trials designed to evaluate abstinence and other outcomes during smoking cessation reported effects of naltrexone on daily or weekly smoking during and/or after treatment with naltrexone. ${ }^{19} 23-2529$ Three studies did not find any association between naltrexone and number of cigarettes smoked among continuing smokers, ${ }^{21} 22{ }^{25}$ another reported cigarettes per week increased more in the placebo group compared to the naltrexone group at the $100 \mathrm{mg}$ dose of naltrexone, ${ }^{19}$ and two studies reported 
Table 2 Naltrexone versus placebo (single pharmacotherapy or adjunct to NRT), abstinence at longest follow-up

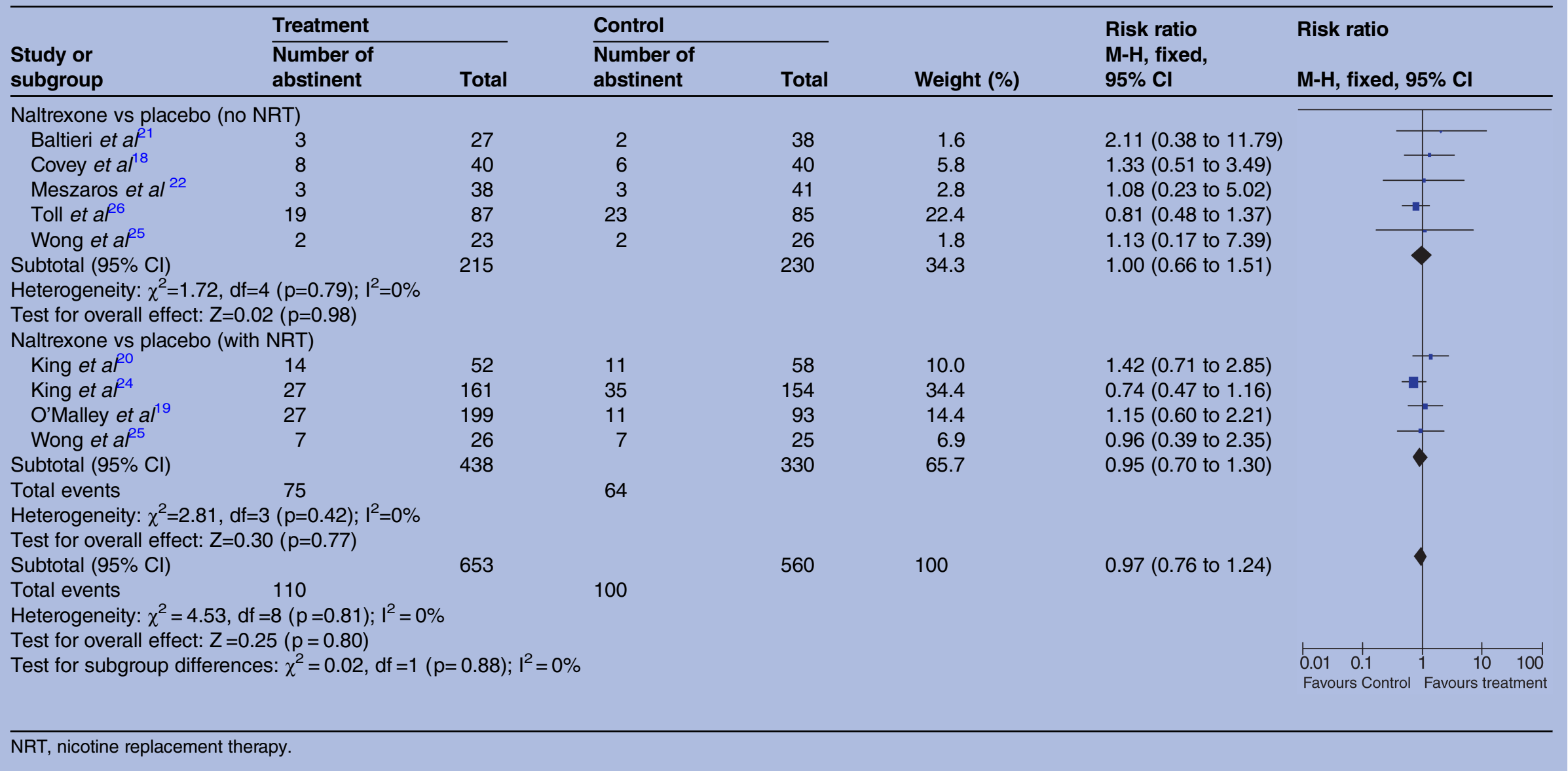


Table 3 Naltrexone versus placebo (single pharmacotherapy or adjunct to NRT), abstinence at end of treatment (short-term outcomes)

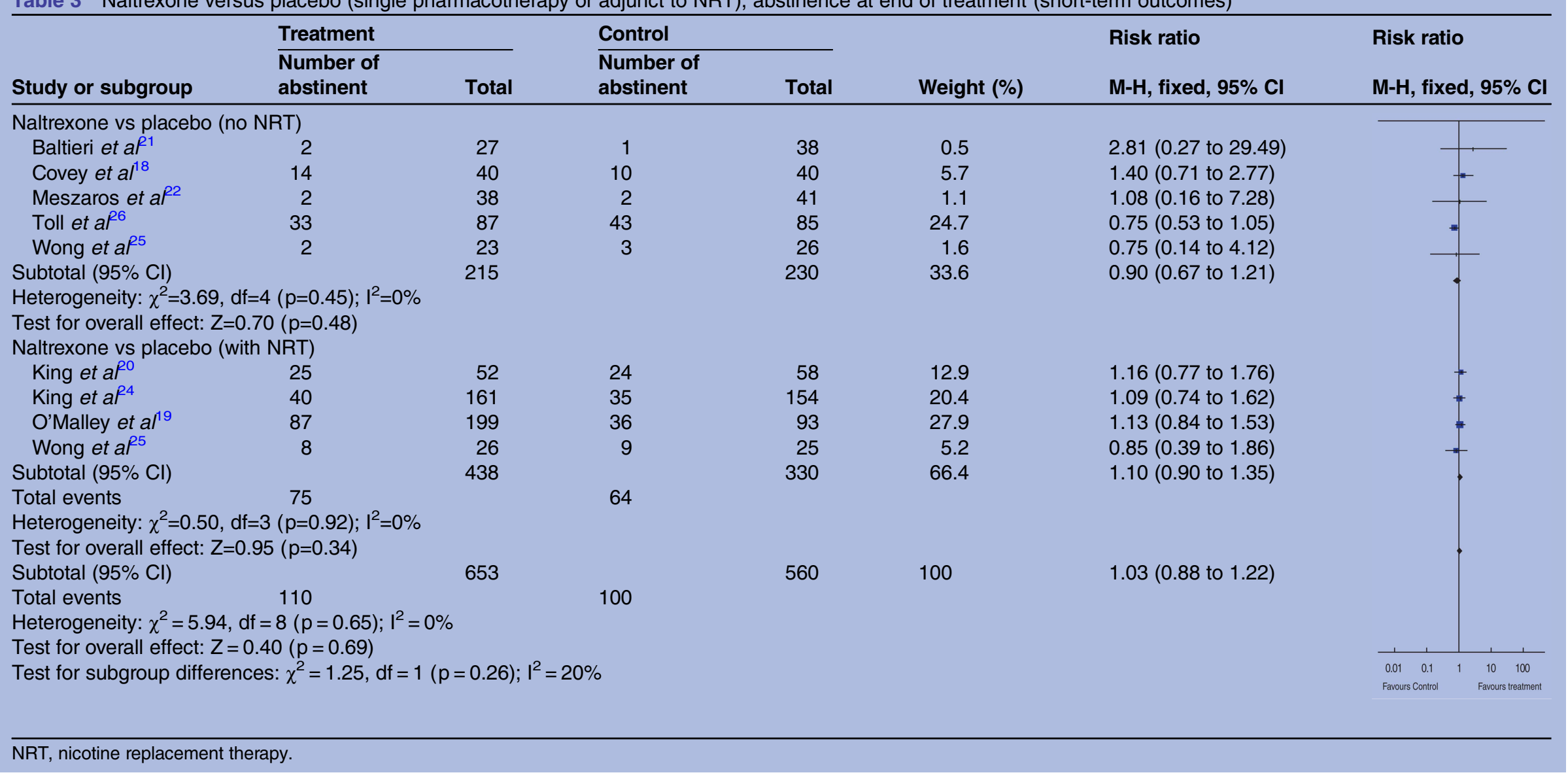


significantly lower weekly cigarettes smoked in the naltrexone (vs placebo) arms of the respective trials. ${ }^{23} 24$ For naloxone, two studies reported significant reductions in number of cigarettes smoked relative to placebo $^{42} 46$ and one study did not find an effect over a wide range of dosages for any measure of cigarette smoking, including number of cigarettes, number of puffs or expired air CO. ${ }^{49}$ With buprenorphine, two studies found an increase in cigarette consumption associated with buprenorphine. 5051

\section{DISCUSSION}

Eight double-blinded, randomised controlled trials of naltrexone with a total of 1213 adult smokers reported long-term abstinence data and 11 reported short-term outcomes. The point estimate for the risk ratio of the long-term effect of cessation pooling all studies, $\mathrm{RR}=0.97$, suggests that naltrexone has no effect on abstinence. Further, there was no benefit of naltrexone relative to placebo for smoking cessation whether used alone or in combination with NRT. The $95 \%$ CI 0.76 to 1.24 indicates that the likelihood of any clinically important effect is very small. By comparison, the RR of longterm abstinence for NRT from 117 trials with over 50000 participants was 1.60 (95\% CI 1.53 to 1.68$).{ }^{3} \mathrm{We}$ also know that one industry-sponsored naltrexone trial remains unpublished, the likelihood being that it too did not detect evidence of benefit ( $\mathrm{R}$ Croop, personal communication). The results suggest that further research is only likely to make the CI narrower around no effect. A secondary analysis of pooled short-term outcomes also showed no evidence of a treatment effect. Including three randomised clinical trials that only reported short-term effects, with a total of 116 participants, did not alter this conclusion.

While we were unable to meta-analyse sex-specific effects including data from all eight trials, there was no compelling or consistent evidence of robust sex differences in efficacy for naltrexone. Although not an endpoint of this systematic review, two trials reported significant benefits of naltrexone for reducing postcessation weight gain, ${ }^{18}{ }^{20}$ while one did not. ${ }^{24}$ A separate Cochrane review showed a modest benefit of naltrexone on reduced postcessation weight gain at end of treatment (mean difference $-0.78 \mathrm{~kg}, 95 \%$ CI -1.52 to $-0.05, \mathrm{~N}=2$ trials), with insufficient data to assess the effects at 6 or 12 months. ${ }^{52}$ There were mixed results from individual trial as to whether opioid antagonists reduced nicotine withdrawal symptoms, the reinforcing effects of nicotine and tobacco or cigarette consumption, but the heterogeneity of methods and reporting precluded use of meta-analytic techniques.

\section{CONCLUSIONS}

While it would seem biologically plausible that opioid antagonists may support smoking cessation vis-à-vis attenuation of positive reinforcement, the current evidence suggests that naltrexone provides no benefit for immediate or sustained smoking cessation. The neurobiology of nicotine addiction is complex and involves interactions between multiple neurotransmitter systems. ${ }^{53}$ Unequivocal benefits have been reported for other classes of smoking cessation medications (ie, nicotine replacement, bupropion and varenicline) with different mechanisms of action in large meta-analyses of scores of clinical trials. ${ }^{3-5}$ However, based on data from eight trials and over 1200 individuals, there is no evidence of a therapeutic effect of naltrexone alone or as an adjunct to NRT on short-term or long-term smoking abstinence rates. While further trials may narrow the confidence limits, they are unlikely to change the conclusion of lack of benefit.

Acknowledgements The authors would like to thank Dr Baltieri, Dr Batki, Dr Hutchison, Dr Niaura, Dr O'Malley and Dr Szombathyne-Meszaros for assistance with providing additional information or data on available studies. They also thank Monaz Mehta for her editorial contributions.

Contributors All authors contributed to this work. SPD designed the study, implemented all methods and guided interpretation of the results. SPD and IMC participated in the drafting and editing of the paper at every stage. SPD, TL, AEE and JJP posed the question, coordinated the research team and participated in all stages of the analysis and drafting of the manuscript. SPD, TL, LFS and JJP assisted in study design and extraction of data and advised on the analysis methods.

Funding This research received no specific grant from any funding agency in the public, commercial or not-for-profit sectors. Support for Dr David and Ms Chu provided by a research stipend from the James C Puffer,

MD/American Board of Family Medicine/Institute of Medicine Anniversary Fellowship.

Competing interests Support to SPD from National Institute on Drug Abuse grant PHS no. R01-DA017441. JJP has served on ad hoc scientific advisory and grant review boards for Pfizer and has a Pfizer funded investigator initiated research award.

Provenance and peer review Not commissioned; externally peer reviewed.

Data sharing statement Unpublished data included in this report are available from the corresponding author upon request.

Open Access This is an Open Access article distributed in accordance with the Creative Commons Attribution Non Commercial (CC BY-NC 3.0) license, which permits others to distribute, remix, adapt, build upon this work noncommercially, and license their derivative works on different terms, provided the original work is properly cited and the use is non-commercial. See: http:// creativecommons.org/licenses/by-nc/3.0/

\section{REFERENCES}

1. USDHS. A report of the surgeon general: how tobacco smoke causes disease: The Biology and Behavioral Basis for Smoking-Attributable Disease. Atlanta, GA: U.S. Department of Health and Human Services, 2010.

2. Fiore MC, Jaen CR, Baker TB, et al. Treating tobacco use and dependence: 2008 update US Public Health Service Clinical Practice Guideline executive summary. Respir Care 2008;53:1217-22.

3. Stead LF, Perera R, Bullen C, et al. Nicotine replacement therapy for smoking cessation. Cochrane Database Syst Rev 2012;11: CD000146.

4. Hughes JR, Stead LF, Lancaster T. Antidepressants for smoking cessation. Cochrane Database Syst Rev 2007:1:CD000031.

5. Mills EJ, Wu P, Lockhart I, et al. Comparisons of high-dose and combination nicotine replacement therapy, varenicline, and bupropion for smoking cessation: a systematic review and multiple treatment meta-analysis. Ann Med 2012;44:588-97.

6. Gourlay SG, Stead LF, Benowitz NL. Clonidine for smoking cessation. Cochrane Database Syst Rev 2004;3:CD000058. 
7. Meyer MC, Straughn AB, Lo MW, et al. Bioequivalence, dose-proportionality, and pharmacokinetics of naltrexone after oral-administration. J Clin Psychiatry 1984;45:15-19.

8. O'Malley S, Croop R, Wroblewski J, et al. Naltrexone in the treatment of alcohol dependence: a combined analysis of two trials. Psychiatr Ann 1995;25:681-8.

9. Volpicelli JR, Alterman Al, Hayashida M, et al. Naltrexone in the treatment of alcohol dependence. Arch Gen Psychiatry 1992:49:876-80.

10. Biala G, Budzynska B, Kruk M. Naloxone precipitates nicotine abstinence syndrome and attenuates nicotine-induced antinociception in mice. Pharmacol Rep 2005;57:755-60.

11. Isola R, Zhang HL, Duchemin AM, et al. Met-enkephalin and preproenkephalin mRNA changes in the striatum of the nicotine abstinence mouse. Neurosci Lett 2002;325:67-71.

12. Malin DH, Lake JR, Carter VA, et al. Naloxone precipitates nicotine abstinence syndrome in the rat. Psychopharmacology 1993;112:339-42.

13. Malin DH, Lake JR, Payne MC, et al. Nicotine alleviation of nicotine abstinence syndrome is naloxone-reversible. Pharmacol Biochem Behav 1996;53:81-5.

14. Goodrich PM. Naloxone hydrochloride: a review. AANA J 1990;58:14-16.

15. About Buprenorphine Therapy. Washington, DC: US Department of Health and Human Services, 2013.

16. David SP, Lancaster T, Stead LF, et al. Opioid antagonists for smoking cessation. Cochrane Database Syst Rev 2013;6:CD003086.

17. Higgins J. Assessing risk of bias in included studies. In: Higgins J, Altman DSterne J, eds. Cochrane handbook for systematic reviews of interventions version 5.1.0. The Cochrane Collaboration, 2011. http://handbook.cochrane.org (accessed 10 March 2014).

18. Covey L, Glassman A, Stetner F. Naltrexone effects on short-term and long-term smoking cessation. J Addict Dis 1999;18:31-40.

19. O'Malley SS, Cooney JL, Krishnan-Sarin S, et al. A controlled trial of naltrexone augmentation of nicotine replacement therapy for smoking cessation. Arch Intern Med 2006;166:667-74.

20. King $\mathrm{A}$, de Wit $\mathrm{H}$, Riley RC, et al. Efficacy of naltrexone in smoking cessation: a preliminary study and an examination of sex differences. Nicotine Tob Res 2006;8:671-82.

21. Baltieri DA, Daro FR, Ribeiro PL, et al. Effects of topiramate or naltrexone on tobacco use among male alcohol-dependent outpatients. Drug Alcohol Depend 2009;105:33-41.

22. Meszaros Z, Dimmock JA, Ploutz-Snyder R, et al. Oral naltrexone treatment for alcohol dependence in schizophrenia is not effective for smoking cessation. Special Issue: Abstracts of the 33rd Annual Scientific Meeting of the Research Society on Alcoholism, 26-30 June 2010, San Antonio, TX, USA. Alcohol Clin Exp Res 2010;34: Abstract 176a.

23. Toll B, O'Malley S. Testing the effectiveness of low dose naltrexone for smoking cessation and minimization of post-cessation weight gain, 2010.

24. King AC, Cao D, O'Malley SS, et al. Effects of naltrexone on smoking cessation outcomes and weight gain in nicotine-dependent men and women. J Clin Psychopharmacol 2012;32:630-6.

25. Wong GY, Wolter TD, Croghan GA, et al. A randomized trial of naltrexone for smoking cessation. Addiction 1999;94:1227-37.

26. Toll BA, White M, Wu R, et al. Low-dose naltrexone augmentation of nicotine replacement for smoking cessation with reduced weight gain: a randomized trial. Drug Alcohol Depend 2010;111: $200-6$.

27. Byars JA, Frost-Pineda K, Jacobs WS, et al. Naltrexone augments the effects of nicotine replacement therapy in female smokers. $J$ Addict Dis 2005;24:49-60.

28. Krishnan-Sarin S, Meandzija B, O'Malley S. Naltrexone and nicotine patch in smoking cessation: a preliminary study. Nicotine Tob Res 2003:5:851-7.

29. Toll B, Wu R, Meandzija B, et al. Naltrexone and varenicline: weight gain and tolerability in smokers [POS2-18]. Society for Research on Nicotine and Tobacco 16th Annual Meeting. Baltimore, MD, 2010.
30. Sutherland G, Stapleton JA, Russell MA, et al. Naltrexone, smoking behaviour and cigarette withdrawal. Psychopharmacology 1995; 120:418-25.

31. Houtsmuller E, Clemmey L, Sigler L, et al. Effects of naltrexone on smoking and abstinence. Nida Res Monogr 1996;174:68.

32. Brauer LH, Behm FM, Westman EC, et al. Naltrexone blockade of nicotine effects in cigarette smokers. Psychopharmacology 1999;143:339-46.

33. King AC, Meyer PJ. Naltrexone alteration of acute smoking response in nicotine-dependent subjects. Pharmacol Biochem Behav 2000;66:563-72.

34. Lee YS, Joe KH, Sohn IK, et al. Changes of smoking behavior and serum adrenocorticotropic hormone, cortisol, prolactin, and endogenous opioids levels in nicotine dependence after naltrexone treatment. Prog Neuropsychopharmacol Biol Psychiatry 2005;29:639-47.

35. Knott VJ, Fisher DJ. Naltrexone alteration of the nicotine-induced EEG and mood activation response in tobacco-deprived cigarette smokers. Exp Clin Psychopharmacol 2007;15:368-81.

36. Caskey N, Olmstead R, Jarvik M, et al. The acute effects of low dose naltrexone on ad lib smoking in normal heavy smokers (PO2 77). Society for Research on Nicotine and Tobacco 7th Annual Meeting. Seattle, WA, 2001

37. Hutchison KE, Monti PM, Rohsenow DJ, et al. Effects of naltrexone with nicotine replacement on smoking cue reactivity: preliminary results. Psychopharmacology 1999;142:139-43.

38. Epstein AM, King AC. Naltrexone attenuates acute cigarette smoking behavior. Pharmacol Biochem Behav 2004;77:29-37.

39. Rohsenow DJ, Monti PM, Hutchison KE, et al. High-dose transdermal nicotine and naltrexone: effects on nicotine withdrawal, urges, smoking, and effects of smoking. Exp Clin Psychopharmacol 2007;15:81-92.

40. Ray LA, Miranda R, Kahler CW, et al. Pharmacological effects of naltrexone and intravenous alcohol on craving for cigarettes among light smokers: a pilot study. Psychopharmacology 2007;193:449-56.

41. Wewers M, Dhatt R, Tejwani G. Naltrexone administration influences cigarette smoking behaviour. Nicotine Tob Res 1998;1:112-13.

42. Gorelick D, Rose J, Jarvik M. Effect of naloxone on cigarette smoking. J Subst Abuse 1988;1:153-9.

43. Krishnan-Sarin S, Rosen MI, O'Malley SS. Naloxone challenge in smokers. Preliminary evidence of an opioid component in nicotine dependence. Arch Gen Psychiatry 1999;56:663-8.

44. Ray R, Jepson C, Patterson F, et al. Association of OPRM1 A118G variant with the relative reinforcing value of nicotine. Psychopharmacology 2006;188:355-63.

45. Wewers ME, Dhatt R, Tejwani GA. Naltrexone administration affects ad libitum smoking behavior. Psychopharmacology 1998;140:185-90.

46. Karras A, Kane JM. Naloxone reduces cigarette smoking. Life Sci 1980;27:1541-5.

47. Olmstead R, Caskey N, Madsen D, et al. The acute effects of low dose naltrexone on ad lib smoking in normal heavy smokers and chippers. Proceedings for the Society of Research on Nicotine and Tobacco 8th Annual Meeting. Savannah, GA, 2002.

48. Rohsenow DJ, Monti PM, Colby SM, et al. Naltrexone treatment for alcoholics: effect on cigarette smoking rates. Nicotine Tob Res 2003:5:231-6

49. Nemeth-Coslett R, Griffiths R. Naloxone does not affect cigarette smoking. Psychopharmacology 1986;89:261-4.

50. Mello NK, Lukas SE, Mendelson JH. Buprenorphine effects on cigarette smoking. Psychopharmacology 1985;86:417-25.

51. Mutschler NH, Stephen BJ, Teoh SK, et al. An inpatient study of the effects of buprenorphine on cigarette smoking in men concurrently dependent on cocaine and opioids. Nicotine Tob Res 2002;4:223-8.

52. Farley AC, Hajek P, Lycett D, et al. Interventions for preventing weight gain after smoking cessation. Cochrane Database Syst Rev 2012;1:CD003086.

53. Benowitz NL. Nicotine addiction. N Engl J Med 2010;362:2295-303. 